\title{
A condição errante do desejo: os imigrantes, migrantes, refugiados e a prática psicanalítica clínico-política*
}

\author{
Miriam Debieux Rosa \\ Sandra Letícia Berta \\ Taeco Toma Carignato \\ Sandra Alencar
}

Este artigo pretende avançar na sustentação teórica sobre a prática psicanalítica clínico-política, campo epistemológico ético e político que leva em conta as especificidades dos sujeitos e as vicissitudes de seus processos em contextos de exclusão e violência. A partir da experiência com imigrantes, formula as bases de um trabalho centrado na clínica do traumático mais do que na clínica do sintoma e focaliza as particularidades da escuta psicanalítica nesses contextos, assim como as intervenções coletivas.

Palavras-chave: Clínica do traumático, prática psicanalítica clínicopolítica, imigrantes, intervenções coletivas

* Apresentado em versões nas reuniões científicas: Congresso Internacional de Psicopatologia Fundamental, Belém, PA, setembro de 2006; IX Congresso Brasileiro de Psicopatologia Fundamental, Niterói, RJ, em setembro de 2008; VII Jornada Corpolinguagem: um retorno a Freud, Campinas, SP, em outubro de 2007.

A pesquisa contou com o apoio financeiro do Fundo de Cultura e Extensão Universitária do Instituto de Psicologia da Universidade de São Paulo, para o Laboratório Psicanálise e Sociedade do Departamento de Psicologia Clínica. 
Neste artigo pretendemos avançar na sustentação teórica sobre a prática psicanalítica possível junto àquelas pessoas que passam por experiências de trauma e luto, muitas vezes, luto impedido ou negado, provocadas por situações sociopolíticas ou econômicas insustentáveis. Utilizamos, para este desenvolvimento, experiências de atendimento psicanalítico em várias instituições públicas e em comunidades marcadas pela exclusão social e política, assim como do atendimento de imigrantes, migrantes e refugiados. ${ }^{1}$ Visamos transmitir uma prática psicanalítica clínico-política, campo epistemológico ético e político que leva em conta as especificidades dos sujeitos e as vicissitudes de suas demandas em contextos de exclusão e violência e que abre inúmeras questões.

Partiremos da reflexão sobre aquelas pessoas que passam por deslocamentos migratórios forçados destacando um tipo de migração, a que diz respeito à errância como condenação, tal como Ahashverus, o Judeu Errante. Este personagem, segundo Fucks (2000, p. 159), "é a metáfora do excluído que, por imposição do outro, está destinado a vagar sem pouso”. Diferenciamos esta situação da migração que é o próprio movimento de busca da diversidade, de tornar-se outro. Pretendemos apontar que há especificidade neste trabalho, centrado na clínica do traumático mais do que na clínica do sintoma, como vem sendo desenvolvido a partir do artigo "Uma escuta psicanalítica das vidas secas” (Rosa, 2002), que trata do atendimento psicanalítico a pessoas em desamparo social e discursivo.

\section{Deslocamentos territoriais e psíquicos e a condição errante do desejo}

A dimensão trágica do migrante encena algo comum a todos, pois todos somos sujeitos exilados, desenraizados de nós mesmos, constituídos pelo desconhecimento enigmático da dimensão inconsciente. Freud, no texto "Moisés e o monoteísmo” (1939), defende as vicissitudes da errância e do nomadismo do desejo, mostrando que a sua precedência sobre a sedentarização marca o povo judeu. Busca na experiência da errância enquanto ato uma metáfora

1. Abrigados na Casa do Migrante, albergue mantido por missionários carlistas (ordem religiosa que se dedica exclusivamente às questões da migração), e no CAMI (Centro de Apoio aos Migrantes).

Rev. Latinoam. Psicopat. Fund., São Paulo, v. 12, n. 3, p. 497-511, setembro 2009 
da errância do sujeito pelo deserto da libido. Concordamos com Fuks (2000) quando escreve:

Não seria descabido dizer que a experiência analítica oferece um espaço aberto ao sujeito para que ele viva a aventura de exilar-se de si, de inventar-se outro, de voltar-se não idêntico. Aventura que se passa no estranho "país do Outro", ou seja, alhures além do semelhante, do idêntico e do espelho e que faz com que o analisando experimente desterritorializações sucessivas de uma posição subjetiva a outra. (p. 85)

As migrações territoriais, os atos de errância e nomadismo, não são maldição ou bênção, mas uma possibilidade do sujeito que, em seu movimento de exílio, regresso e solidão, pode estabelecer uma abertura radical e primeira ao Outro. No entanto, tal exílio e identidade ganham especificidades nos diferentes processos de deslocamento. A migração territorial é processo que mobiliza e enlaça motivações sociais, políticas, econômicas e subjetivas - a relação com a nova terra e os novos laços terão as marcas desses processos. Essa condição tem a potência de relativizar toda relação fixa do sujeito com o poder de modo que o olhar do exilado, migrante ou refugiado pode, por sua exterioridade, ser perturbador para a cidade, gerando hostilidades e violências. Também pode assim abalar a identidade do sujeito, tomada aqui como a ficção de si mesmo. Por isto mesmo, o exílio pode levar o indivíduo ou grupo a se enclausurar nas chamadas "comunidades étnicas”.

Para levantar as coordenadas sobre a função dos deslocamentos, vamos retomar a estratégia utilizada em trabalho anterior, "Metáforas do deslocamento" (Rosa et al. 2007), em que relacionamos o deslocamento enquanto fenômeno migratório com o deslocamento como uma das leis do inconsciente freudiano e sua versão em Lacan, a metonímia. Especificamos a relação deslocamento/metonímia com os avatares do desejo, desenvolvendo a hipótese de que as dimensões diacrônicas e sincrônicas do discurso, expressas pela metáfora e pela metonímia, demonstram a condição itinerante do desejo em tensão quanto à ficção do sujeito construída, mas desconstruída e reinventada pelo desejo. Apesar de inseparável da condição social em que ocorre, refletimos, a partir de uma separação artificial do processo social específico de cada grupo social que emigra, sobre as condições de possibilidade do sujeito como

... um ser regido ora pela antecipação estruturante, ora pela significação retroativa que o recoloca em posição de saber. O seu movimento, próprio da condição desejante, torna a apreensão de si e do mundo marcada pelo desconhecimento e reconhecimento e, portanto, tornando sucessiva e concomitante, a alienação e a verdade, a identidade e a subjetividade, presentes em sua condição de ser. (Rosa, 1998, p. 126)

Rev. Latinoam. Psicopat. Fund., São Paulo, v. 12, n. 3, p. 497-511, setembro 2009 
Nessa bipolarização discursiva, a metonímia mantém o deslizamento significante do discurso e marca a condição errante e nômade do desejo. Trabalhamos a relação deslocamento e condensação, metonímia e metáfora para levantar questões sobre os apelos migratórios e identitários pensados como diversidade de expressão dos sujeitos, como modalidades de trabalho do sujeito na direção do desejo. Ambos são concomitantes e compõem a historicização do sujeito. Dissociados, os processos podem gerar, de um lado, um movimento contínuo sem ponto de báscula, o que pode resultar no desenraizamento do sujeito; ou, de outro, levar a uma identidade cristalizada alienante que retira o sujeito de sua condição desejante. Ou seja, o sujeito se constitui na alternância entre o movimento metonímico do desejo e a cristalização sintomática em identidades.

Com essa estratégia, pode-se separar o deslocamento territorial e seu potencial inovador das condições contingentes de penúria que são geradas por questões sociais e não intrínsecas ao processo migratório. Destacamos o momento do deslocamento como de suspensão das certezas simbólicas e imaginárias do Eu. Portanto, a migração pode remeter ao desejo humano, através da cadeia metonímica de associações, de significações e de substituições metonímicas que contornam o desejo do Outro. Nessa direção, pode-se ir ao país do Outro movido pela premência de romper com alienação mortífera, de mudar de lugar subjetivo desconstruindo ficções do Eu, desencadeando movimentos que possibilitem experimentar outros destinos, novas dimensões da vida.

O risco dessa aventura, especialmente quando forçada e associada a processos de exclusão e abuso social e político, é de, como ocorre com alguns dos usuários da Casa do Migrante, dissociar os processos metafóricos e metonímicos. De um lado, erram sem destino; do outro lado, o sujeito circunscrito ao ponto de basta, sem o necessário deslizamento do significante que o identifica a determinados grupos sociais, é o sujeito fortemente alienado a uma identidade nacional ou étnico-religioso-cultural. A ameaça da desterritorialização, não necessariamente produzida nas migrações, pode acarretar na constituição de uma territorialidade circunscrita por uma demanda fixa e sem possibilidade de dialetização; nível sincrônico do discurso que alude ao ponto de basta que circunscreve, revela e veda a verdade do sujeito. Muitas vezes o apego à territorialização aparece imaginariamente como garantia de pertencimento.

Essa condição de imigrante e de refugiado propicia, sem dúvida - e é o que observamos -, toda sorte de manipulações e abusos. A questão política se destaca, pois as pessoas que estão em situação irregular, não documentadas, são levadas a agir respondendo à urgência. Pressionado, desenraizado, o sujeito deixa-se emaranhar nas garras do instantâneo, do reagir em vez do agir. Então o perdido torna-se um obstáculo e cristaliza-se, seja numa emissão de documentos, em empregos precários, casamentos arranjados, em filhos gerados para legalização, 
estratégias que supostamente decidiriam a posição do sujeito. No caso do refugiado, a emissão de um documento situa-o na condição de “protegido”, o que nem sempre corresponde à realidade do fato, pois, na maioria das vezes, o país o recebe, mas não lhe oferece meios para a sobrevivência econômica.

Nota-se que certos deslocamentos sucessivos promovem a suspensão da função pacificadora e estabilizadora do Eu, produtora de um apoio identitário. Tal suspensão reverte no abrandamento das leis e valores que favoreceriam a dimensão desejante, mas dificultam marcar o lugar de onde podem estabelecer laços com o outro. Além disso, os abalos identificatórios afetam especificamente o eu, seja no registro imaginário (eu ideal), seja no registro simbólico (ideal do eu). Eles podem ser libertários, mas também desorientadores. E facilitam a aceitação do mínimo para a subsistência, dispensados os artifícios narcísicos, que podem tomar forma de conformidade e submissão.

As vicissitudes da experiência de ser Outro podem ser sustentadas pela evocação da palavra, pela escrita e por outros modos de transmissão que a escuta clínica pode propiciar. $\mathrm{O}$ analista testemunha o exílio necessário que cada paciente experimenta como condição do advento da sua palavra. Ser sujeito não é essência, mas movimento, errância, um caminhar incessante em seu pensamento, vida sem repouso, sem medir distâncias. Mas há especificidades nas estratégias clínicas quando o exílio ou exclusão é imposto pelo Outro que obriga a vagar sem pouso e o tratamento não é demandado.

\section{A condição errante do desejo e a clínica do traumático}

Cabe destacar que, ao falarmos de deslocamento territorial, diferenciamos os processos por sua dimensão de escolha. Embora mais óbvio no caso dos exilados e refugiados, reconhecemos a complexidade da situação na escolha "forçada” dos imigrantes e migrantes que aliam os movimentos do sujeito à expulsão política e social. Muitos que migram buscam, de certa forma, ampliar horizontes, conquistas, promover deslocamentos psíquicos ou mesmo romper apegos melancólicos a estilos de vida estagnados e superados. Mas são nas migrações forçadas pela violência e miséria, como no caso principalmente dos refugiados ou dos migrantes, que a dimensão do perdido e a dificuldade de se localizar no mundo tomam um lugar primordial e podem promover efeitos de desenraizamento ou de desterritorialização.

Ficam caracterizadas situações de precariedade e desproteção sociopolítica e discursiva. Mário Pujó (2000) caracteriza a fragilização das estruturas discursivas que suportam o vínculo social, no que rege a circulação dos valores, ideais, 
tradições de uma cultura e resguardam o sujeito do real de desamparo discursivo. Esse jogo discursivo expõe o sujeito ao risco de confrontação com o traumático - aquilo que está fora de sentido. A exposição traumática é dupla: por um lado, sua ocorrência é facilitada; por outro, os recursos necessários à elaboração do trauma encontram-se diminuídos, promovendo efeitos de dessubjetivação. Isto lembra o que Colette Soler (2004) especifica ao dizer que o traumatismo participa de uma temporalidade específica que perpetua o instante traumático:

O traumatismo se impõe em uma temporalidade de ruptura: o sujeito não tem nele a mínima parte, isso lhe cai em cima. É uma temporalidade de instante, mas de um instante que não se esquece facilmente, enquanto existem tantos instantes que se evaporam no esquecimento e a partir do qual se instala uma constância, como uma onda que se propaga rebelde ao apagamento. De alguma forma um instante que engendra algo, uma perpetuidade. (p. 55)

A fixação ao instante traumático promove uma resposta subjetiva bem específica, a saber: o silenciamento, a mordaça da palavra. Assim, uma constante nessas situações é o silenciamento dos sujeitos entendida por Rosa (2002) como: "esta suspensão temporária, às vezes da vida inteira, mas temporária e não estrutural, um modo de resguardo do sujeito ante a posição de resto na estrutura social. Uma proteção necessária para sobrevivência psíquica, uma espera, uma esperança” (p. 45). Nesses casos não é possível um trabalho aos moldes de uma clínica do sintoma, mas pode-se realizar intervenções que podemos chamar de clínica do traumático nos casos em que o sujeito não construiu ainda uma resposta metafórica, um sintoma através do qual possa falar de seu sofrimento e endereçar uma demanda.

É necessário, então, um esclarecimento. A clínica do traumático não é específica das intervenções clínico-políticas às quais nos referimos. As respostas ao trauma, na psicanálise, têm sido apresentadas em dois níveis: fantasia e sintoma. Frisando aqui outro enfoque, que ressalta um tempo subjetivo no qual o trauma, esse instante perpétuo, toma conta de toda possibilidade de uma questão subjetiva, encontrando como resposta a repetição do silêncio, a perpetuação da angústia ou o impedimento de processos subjetivos do luto.

Se nos deparamos com o silenciamento, podemos dar um passo a mais, abordando a sua relação com a angústia e o luto em determinadas situações sociais e políticas. O pano de fundo dessa questão é a manipulação da vida e da morte no campo social, limite da ética. Silenciamento observado na imigração japonesa por Carignato (2002); nos deslocamentos migratórios, que lançam os sujeitos em uma errância sem fim (Rosa et al., 2007); associado à particularidade do luto e angústia promovidos pelo desaparecimento das pessoas contrárias à ditadura na Argentina (Berta, 2007); constatado na produção do luto impedido em 
situações atendidas por Alencar (2006) em São Mateus, periferia de São Paulo o luto é impedido quando o ser querido morto (ou o país de origem) é socialmente desqualificado, como bandido ou traficante, louco, pobre, miserável.

Berta e Rosa (2005) sustentam que frente ao perdido, frente à perda das referências identificatórias, existe um primeiro tempo que pode ser pensado tendo como referente o conceito de angústia. A angústia é o afeto que não engana e diz respeito àquilo que o sujeito não pode articular em significantes; é sinal de um Real impossível de ser simbolizado. Jacques Lacan, no seu Seminário A angústia (1963), partindo do desamparo inicial, indica as diferentes respostas do sujeito em sua relação ao Outro. "O encontro com situações que evocam esse desamparo inicial provoca angústia, não como manifestação sintomática (caso da angústia neurótica em Freud), tampouco como fuga, mas como um tempo no qual o sujeito custa a se localizar e que, por esta razão, é vinculado ao sentimento de estranheza, o unheimlich freudiano" (p. 54).

Este tempo no qual o sujeito custa a se localizar tem efeitos na sua posição subjetiva e no laço social. Entre a angústia e o desejo, é necessária a elaboração do luto em face do perdido, pois dessa maneira o sujeito reconstitui não somente sua imagem, mas recompõe o lugar a partir do qual se vê amável para o Outro (ideal do eu), reafirmando uma posição que lhe permita localizar-se no mundo. Para recompor um lugar discursivo, para que faça laço social, é preciso reconstruir a história perdida na memória, reconstrução que já implica uma deformação, permitindo o luto e uma resposta à ficção, uma reinterpretação do passado que modifique o seu lugar.

O luto impedido ocorre em situações de violência, podendo gerar uma posição melancólica em que o sujeito não nomeia a dor, que não passa. É, como diz Freud (1917) da melancolia, "uma ferida aberta que empobrece a libidinização do ego identificado ao objeto abandonado... a sombra do objeto caiu sobre o ego" (p. 281). O processo de luto e de melancolia, ensina Freud, supõe um primeiro tempo de negação da perda, recolhimento necessário para preservar o objeto vivo e ativo no eu. Uma das diferenças do luto e melancolia é que, no primeiro, o sujeito aparentemente sabe o que significava para ele o objeto perdido, enquanto isto se torna impossível ao melancólico. Ele sabe da perda, mas vive como se esta não houvesse se processado, em um certo autismo, isolamento da realidade e paradoxalmente realçando os traços do objeto perdido.

É o que acontece com o imigrante que, no primeiro tempo de negação da perda, idealiza os objetos, as pessoas, a natureza e as relações com o país de origem, tentando manter vivo um passado que deixa de ser, para ele, passado. O choque com as perdas acontece no retorno em que ele não reconhece o que deixou para trás - pessoas e coisas - e também não se reconhece no passado que se transformou. Também pode ocorrer que em vez de luto fiquem ruminando e 
idealizando reminiscências que se presentificam adiando o corte que as transformaria em memórias e história. No caso das migrações, o luto se apresenta como "saudades da terra natal”, em que o sujeito não se reconhece em suas perdas, pois é absorvido em um modo de produção alucinante ou degradante. Não tendo mais o controle do seu corpo que é acoplado ao sistema produtivo, sente escaparem-lhe os pensamentos que se voltam constantemente ao passado, uma vez que o presente é penoso e o futuro indefinido. Nesse sentido, o luto se desloca e se efetiva com a primeira perda no país de imigração - geralmente decepções amorosas, com irrupções de sentimentos extremamente narcísicos -, ou ganha contornos melancólicos na maturidade quando os filhos deixam o lar para ganhar a própria vida ou mesmo para emigrar.

O trabalho torna primordial abordar os processos de identificação. A identificação se faz a partir do que se imagina do desejo do Outro - identificar em função do que, ou contra o que, o sujeito pensa ser o desejo do Outro. Se o desejo pode ser imaginado, fantasmado, o sujeito vai encontrar nele as referências necessárias para se definir enquanto objeto do desejo ou a recusa, podendo se orientar. Quando o desejo se torna indefinível o que encontra é o seu fantasma fundamental: ser objeto do desejo do Outro ao qual não se pode dar nome, tornando-nos objeto sem nome, que perdeu a identidade. Na angústia ficam dissolvidos tanto o eu quanto o Outro enquanto suporte identificatório e o desejo se perde sem poder ser nomeado; cria não uma distância entre o eu e o Outro, mas uma oposição (antinomia) entre desejo e demanda, de modo que no lugar da nomeação do objeto surge o gozo no fantasma.

Portanto, a clínica do traumático lança desafios e exige intervenções que caracterizamos como prática psicanalítica clínico-política para abordar a questão da angústia e do luto em sua face política, ou seja, a produção sociopolítica da angústia e do impedimento dos processos subjetivos do luto. Prática que levanta questões metodológicas (individuais e/ou coletivas), armadilhas (intervir em nome do bem do outro) e impasses quanto ao desejo do analista. Apontaremos neste trabalho modalidades de intervenção diante do efeito disruptivo ao sujeito e impeditivo da construção de sua demanda, quando decorrente diretamente da manifestação violenta da face obscena do Outro. Focalizaremos as particularidades da escuta psicanalítica e as intervenções coletivas.

Verificamos na prática clínica que uma forma de amenização das perdas são as confraternizações coletivas em rituais religiosos e profanos, tais como os cultos, os festivais e o carnaval. O que poderia relançar os imigrantes ao autismo cultural pode favorecer o luto, pois na produção dos cultos e das festas populares do país de origem também se localizam as perdas, evidenciando-se, na verdade, uma "criação", uma "re-invenção" do passado. 
Nessa direção Berta (2007) demonstra a importância do movimento das $M a$ dres da Plaza de Mayo para ofertar as precondições para o luto dos desaparecidos na Argentina. Na sua dissertação $O$ exílio: vicissitudes do luto. Reflexões sobre o exílio político dos argentinos (1976-1983), escreve que essas mães contestam o absoluto do regime totalitário saindo às ruas e provocando um corte a partir do qual uma torção mostra o público do que se pretendia privado de cada família dos desaparecidos. Os militares e a polícia ordenaram que as mães marchassem e saíssem da Plaza. Porém, elas não saíram, continuaram a dar a volta ao redor da Pirâmide de Mayo como se, paradoxalmente, contornassem um buraco, que lembra o buraco da angústia que pode sufocar o sujeito. À ordem "marchem, caminhem!!!”, respondem quebrando o imperativo; e num ato transformador criam uma cena pública que modifica não somente o sentido do que se pretendia absoluto, mas também promovem o reconhecimento de um laço possível com um Outro modificado pelo mesmo ato. O luto, que a autora nomeia "luto político", promoveu a "legalização" do luto subjetivo, pois até esse momento os desaparecidos eram uma miragem que assombrava a cena social, negando ou tergiversando a construção de uma realidade - isto é, de uma ficção - que incluía os fatos políticos dessa época na Argentina.

Resta indicar que essas Madres e Abuelas que se opuseram e se opõem ao Governo Militar e suas Forças Armadas testemunham que "não se pode fazer desaparecer o evidente”. Essas marchas são o índice do luto impossível, uma vez que os corpos dos desaparecidos continuam desaparecidos. Podemos, agora sim, afirmar que o luto político contesta a "indecência do luto" de nossa época atual. Essas mães e avós fazem desse impossível alguma nova marca e é nisso que se inscreve $o$ ato transformador que tem um efeito de transmissão no sujeito e no coletivo. (p. 103)

Então, é fato que para tratar o trauma provocado pela intervenção do Outro totalitário que pretende reduzir os homens a restos, nos quais se tentar apagar todas as marcas da subjetividade, é necessária uma elaboração que finque suas bases na reconstituição das leis que norteiam o funcionamento do campo social. Razão pela qual sustentamos que todo fenômeno social traumático deve ser inscrito e elaborado no nível coletivo, sem desmerecer as respostas singulares, que farão do universal o particular.

Alencar (2006), por sua vez, desenvolveu como estratégia a intervenção clínico-política. Através de atendimentos à população, marcada por perdas em situações de violência, ela defronta-se com a substituição do luto por manifestações psicossomáticas e estados diagnosticados por depressões. Os diagnósticos psicológicos e psiquiátricos nas instituições de saúde tendem a ignorar as condições de vida e de perdas expressivas dessas pessoas. A psicanalista constata que cer- 
tos arranjos e discursos sociais que cercam essas pessoas produzem um estado de negação da perda, cujo efeito pode ser estancamento da dor e impedimento do luto - relaciona a desqualificação, pela coletividade, do parente perdido como bandido, pervertido - e o abandono consequente à sua própria dor, gerando efeitos subjetivos indutores de processos melancólicos.

$\mathrm{Na}$ falta do significante que possibilita apresentar a ausência do Outro sob um véu, para promover articulações, no seu lugar, povoam imagens, ao modo da loucura coletiva, imagens que surpreendem a todos e cada um quando a desaparição de alguém não é acompanhada pelos ritos requeridos. Lacan (1958-1959), discutindo sobre Hamlet, oferece a base teórica da importância da comunidade e dos rituais para dar condições para o processamento do luto. A perda rejeitada do simbólico reaparece no real. "Os ritos são a intervenção maciça de todo jogo simbólico que clama a memória dos mortos. O trabalho de luto realiza-se no coletivo, na comunidade. É uma satisfação dada ao que se produz de desordem em razão da insuficiência dos significantes para fazer face ao buraco criado na existência” (inédito). Assim, destaca a dimensão ritual e coletiva como precondição à elaboração individual do luto. A sua supressão é elucidativa da modalidade contemporânea de violência e da degradação social e ética (Agamben, 2002) que atinge o conjunto da sociedade e a enlouquece coletivamente.

Alencar desenvolve elementos para uma prática clínico-política em São Mateus, distrito da periferia do município de São Paulo. A partir do serviço público de saúde, convida associações, movimentos sociais, instituições a fazerem juntos conversas e ações que criassem o novo frente a situações que se apresentavam de forma bruta, violentas. Ocorreram seminários, reuniões, textos foram escritos e distribuídos em feiras e eventos locais, enfim, algo acontecia ali e as pessoas encontravam um espaço de enlaçamento. Esse movimento foi sintetizado em uma caminhada: "Primeira caminhada pela vida em São Mateus”, cujos objetivos eram criar ação coletiva no bairro; homenagear os parentes mortos violentamente na região; criar espaço de expressão, acolhimento e simbolização de perdas. A caminhada finalizou com plantar, cada um, uma flor em uma praça do bairro.

As intervenções que Paulo Endo (USP-SP) coordenou, junto com Edson de Souza (UERS) e Miriam Debieux Rosa (USP-SP) em 2004, por ocasião do assassinato de 10 moradores de rua, seguido de investigação precária, vão nesta direção. Foram realizados eventos na Câmara de São Paulo com várias entidades de movimentos sociais e um Ato Público, no Centro, na cena do crime, um Ritual de Intervenção \& Celebração à Vida, no Pátio do Colégio, ao lado da Praça da Sé.

São exemplos elucidativos, quando não sui generis sobre as modulações de uma clínica que aborda a angústia e o luto em que as práticas psicanalíticas propostas são modalidades de resistência coletiva que permitem resgatar as condi- 
ções para a elaboração do luto. Esses casos revelam as estratégias que levam em consideração as precondições sociopolíticas e subjetivas necessárias para a elaboração do luto, para fazer valer a dimensão do desejo, melhor defesa contra o gozo mortífero. Essas precondições podem ser realizadas na clínica stricto sensu ou através de práticas coletivas, que permitam a produção de ato que toca dimensões do real, simbólico e imaginário, contornando e significando aquilo que, por vezes, é negado socialmente. Restituir um campo mínimo de significantes que possam circular, referidos ao campo do Outro, permite ao sujeito localizar-se e poder dar valor e sentido à sua experiência de dor, articulando um apelo que o retire do silenciamento.

Nas situações de extrema angústia e perda de referenciais identificatórios está incluída a oferta da escuta psicanalítica em que utiliza a presença e a palavra. Presença como testemunha do desenrolar de um processo, como oferta de um campo que possa associar a laços já estabelecidos e desencadear movimentos associativos. Nas palavras de Rosa (2000), a oferta de uma forma de escuta "supõe romper barreiras e resgatar a experiência compartilhada com o outro, deve ser uma escuta como testemunho e resgate da memória” (p. 47).

Falamos de "presença da palavra" em um contraponto com o que Lacan (1964) chamou de "presença do analista”, pois esta última visa aos limites da palavra, o lugar onde o silêncio poderia perpetuar-se e no qual o psicanalista é convocado a suportar e servir de mola ao relançamento das significações. Eis aí onde se verifica o que há do desejo do analista em questão. Nesse sentido, em nossa clínica, a "presença da palavra" que se suporta da "presença do analista" se verifica na diversidade das intervenções: em atividades grupais sobre temáticas, relativas à imigração ou livres, em oficinas de português, em escutas singulares, na presença nos acontecimentos e conflitos com a instituição.

A angústia surge justamente quando não há distância entre a demanda inconsciente e a resposta do Outro, quando se perde a distância entre o enunciado e a enunciação. Portanto, a clínica do traumático convoca o analista a um lugar preciso em relação à angústia - cabe ao analista abrir espaço para a fala, dizer “diga mais” promovendo as condições necessárias para a localização subjetiva. A “presença da palavra” se suporta da "presença do analista” e se verifica na diversidade das intervenções.

Há um sujeito, esta é a aposta psicanalítica. Na atual fase da acumulação capitalista em que se ordena que o sujeito, negado em sua condição desejante, se faça objeto para o funcionamento da ordem econômico-social e política, a escuta psicanalítica pode contribuir para a separação dessa ordenação, para sua movimentação e transformação - é como sujeito marcado pela falta-a-ser que a alteridade, a diferença, não é significada como ameaça, mas como encontro, com o qual se faz o novo. 
Finalizando esta abertura às nossas questões: consideramos que articular tais estratégias clínicas e políticas é fundamentar o enfrentamento do sofrimento nas relações sociais, modo de constatar e denunciar mecanismos de controle, construindo práticas de resistência às manipulações, nas quais a dimensão subjetiva não fique excluída ou silenciada. Acaso não é isso o que o silêncio aponta? Pois existe uma diferença fundamental entre o silêncio mortífero e o silêncio sintomático. Sintomatizar o silêncio - cavado na angústia, no instante perpétuo, no estado melancólico -, é a isso que apontamos nesse tipo de intervenções clínicas.

\section{Referências}

Agamben, G. Homo sacer: o poder soberano e a vida nua - I. Belo Horizonte: Ed. da UFMG, 2002.

Alencar, S. L. de S. Uma experiência em Saúde Pública em São Mateus: algumas reflexões psicanalíticas sobre intervenções em situação de luto coletivo. Congresso Internacional de Psicopatologia Fundamental, Belém, PA, set. 2006.

Berta, S. L. O exílio: vicissitudes do luto. Reflexões sobre o exílio político dos argentinos (1976-1983). 2007. 132 p. Dissertação (Mestrado em Psicologia Clínica). Universidade de São Paulo.

Berta, S. L.; Rosa, M. D. Angústia e luto no exílio político. Revista Textura, São Paulo, ano 5, n. 5, p. 52-56, 2005.

Carignato, T. T. Passagem para o desconhecido: um estudo psicanalítico sobre as migrações entre Brasil e Japão. São Paulo: Via Lettera, 2002.

. Os sintomas da migração. 2004. 167p. Tese (Doutorado em Psicologia Social). Pontifícia Universidade Católica de São Paulo.

et al. Imigrantes, migrantes e refugiados: encontros na radicalidade estrangeira. Revista Interdisciplinar da Mobilidade Humana - REMHU, São Paulo, ano XIV, n. 26, p. 83-118, 2006.

Freud, S. (1917[1915]). Luto e melancolia. Trad. sob a direção de Jayme Salomão. In: Edição Standard Brasileira das Obras Psicológicas Completas de Sigmund Freud. Rio de Janeiro: Imago, 1974. v. XXIII.

. (1939[1934-38]). Moisés e o monoteísmo. Trad. sob a direção de Jayme Salomão. In: Edição Standard Brasileira das Obras Psicológicas Completas de Sigmund Freud. Rio de Janeiro: Imago, 1974. v. XIV.

Fuks, B. Freud e a judeidade: a vocação do exílio. Rio de Janeiro: Jorge Zahar, 2000. Koltai, C. Política e psicanálise: o estrangeiro. São Paulo: Escuta, 2000. 
LACAN, J. (1958-1959). O seminário. Livro VI. O desejo e sua interpretação. Tradução da Associação Psicanalítica de Porto Alegre a partir do texto estabelecido pela Association Freudienne Internationale, 2002.

. (1962-1963). O seminário. Livro X. A angústia. Publicação interna da Associação Freudiana Internacional, Recife, 2002.

. (1964). O seminário. Livro XI. Os quatro conceitos fundamentais da Psicanálise. Tradução M.D.Magno. Rio de Janeiro: Jorge Zahar, 1993.

Pujó, M. Trauma e desamparo. Clínica do desamparo. Revista Psicoanálisis y el Hospital, Buenos Aires, v. 17, p. 29, 2000.

Rosa, M. D. A psicanálise frente à questão da identidade. Psicologia e Sociedade, ABRAPSO, v. 10, n. 1, p. 121-128, 1998.

. Uma escuta psicanalítica das vidas secas. Revista Textura, São Paulo, ano 2, n. 2, p. 42-47, 2002.

et al. Metáforas do deslocamento: imigrantes, migrantes e refugiados e a condição errante do desejo. In: Costa, A.; Rinaldi, D. (Org.). Escrita e psicanálise. Rio de Janeiro: Companhia de Freud, 2007. p. 371-387.

Soler, C. Trauma e fantasia. Stylus: Revista de Psicanálise, Rio de Janeiro, n. 9, p. 45-59, out. 2004.

\section{Resumo}

(La condición errante del deseo: los inmigrantes, emigrantes, refugiados y la práctica psicoanalítica clínico-política)

Este artículo pretende avanzar en la sustentación teórica sobre la práctica psicoanalítica clínico-política, campo epistemológico ético y político que tiene en cuenta las especificidades de los sujetos y las vicisitudes de sus procesos en los contextos de exclusión y violencia. A partir de la experiencia con inmigrantes formula las bases de un trabajo centrado en la clínica de lo traumático, antes que en la clínica del síntoma, enfocando el tema en la escucha psicoanalítica en esos contextos, así como en las intervenciones colectivas.

Palabras claves: Clínica de lo traumático, práctica psicoanalítica clínico-política, inmigrantes intervenciones colectivas

(La condition errante du désir: les immigrés, les migrants, les réfugiés et la pratique psychanalytique clinico-politique)

Cet article vise à contribuer à l'étayage théorique de la pratique psychanalytique politico-clinique, domaine épistémologique moral et politique qui prend en compte les 
spécificités des sujets et les vicissitudes de leurs procédures dans des contextes d'exclusion et de violence. À partir de l'expérience avec des immigrés, nous formulons les bases d'un travail centré sur la clinique du traumatique plutôt que sur celle du symptôme et nous concentrons sur les particularités de l'écoute psychanalytique dans ces contextes, ainsi que sur les interventions collectives.

Mots clés: Clinique du traumatique; pratique psychanalytique politico-clinique; immigrés; interventions collectives

(The errant condition of desire: immigrants, migrants, refugees and clinical-political psychoanalytic practice psychoanalysis)

This article is meant as a contribution to the theoretical underpinnings of clinical and political psychoanalytic practice. This ethical, political and epistemological field that addresses the specificities of subjects and the difficulties related to their processes in contexts of violence and exclusion are discussed. Based on experience with immigrants, migrants and refugees, the text describes the bases of work centered on the clinic of traumatic events, rather than on symptoms, and focuses especially on the particularities of psychoanalytic listening within these contexts. Collective interventions are also discussed.

Key words: Clinic of traumatic events, clinical and political psychoanalytic practice, immigrants, collective interventions

Citação/Citation: Rosa, M.D.; Berta, S.L.; Carignato, T.T., Alencar, S. A condição errante do desejo: os imigrantes, migrantes, refugiados e a prática psicanalítica clínico-política. Revista Latinoamericana de Psicopatologia Fundamental, São Paulo, v. 12, n. 3, p. 497-511, set. 2009.

Editor do artigo/Editor: Prof. Dr. Manoel Tosta Berlinck

\section{Recebido/Received: 12.8.2008 / 8.12.2008 Aceito/Accepted: 1.9.2008 / 9.1.2008}

Copyright: (C) 2009 Associação Universitária de Pesquisa em Psicopatologia Fundamental/ University Association for Research in Fundamental Psychopathology. Este é um artigo de livre acesso, que permite uso irrestrito, distribuição e reprodução em qualquer meio, desde que $\mathrm{o}$ autor e a fonte sejam citados/This is an open-access article, which permits unrestricted use, distribution, and reproduction in any medium, provided the original author and source are credited.

Financiamento/Funding: Os autores declaram ter sido financiados pelo Fundo de Cultura e Extensão Universitária do Instituto de Psicologia da Universidade de São Paulo, para o Laboratório Psicanálise e Sociedade do Departamento de Psicologia Clínica/The authors declare that their work was funded by the Fundo de Cultura e Extensão Universitária do Ins- 
tituto de Psicologia da Universidade de São Paulo for the Laboratório Psicanálise e Sociedade do Departamento de Psicologia Clínica.

Conflito de interesses: Os autores declaram que não há conflito de interesses/The authors declare that has no conflict of interest.

\section{Miriam Debieux Rosa}

Professora de Graduação e Pós-Graduação em Psicologia Clínica da Universidade de São Paulo - USP (São Paulo, SP, Brasil) e em Psicologia Social na Pontifícia Universidade Católica de São Paulo - PUC-SP (São Paulo, SP, Brasil); coordenadora do Laboratório Psicanálise e Sociedade da Universidade de São Paulo - USP e do Núcleo de Pesquisa Violência, Política e Sujeito da Pontifícia Universidade Católica de São Paulo - PUC-SP; coordena projeto Migração e Cultura na Universidade de São Paulo - USP.

Al. Joaquim Eugênio de Lima 1041/72

01403-000 São Paulo, SP, Brasil

e-mail: debieux@terra.com.br

\section{SANDra Leticia Berta}

Mestranda do Departamento de Psicologia Clínica da Universidade de São Paulo - USP (São Paulo, SP, Brasil); membro do Laboratório Psicanálise e Sociedade da mesma Universidade e da Escola de Psicanálise dos Fóruns do Campo Lacaniano-SP (São Paulo, SP); supervisiona projeto Migração e Cultura na Universidade de São Paulo - USP.

Av. Pompéia, 368/21 - Vila Pompéia

05022-000 São Paulo, SP, Brasil

e-mail:bertas@uol.com.br

\section{Taeco Toma Carignato}

Doutora em Psicologia Social pela Pontifícia Universidade Católica de São Paulo - PUC-SP (São Paulo, SP, Brasil); pós-doutoranda em Psicologia Clínica na Universidade de São Paulo - USP (São Paulo, SP, Brasil); membro do Laboratório Psicanálise e Sociedade da Universidade de São Paulo - USP; autora do livro Passagem para o desconhecido. Um estudo psicanalítico entre Brasil e Japão. São Paulo: Via Lettera/Fapesp, 2002; supervisiona projeto Migração e Cultura na Universidade de São Paulo - USP.

Rua Alberto Willo, 146

04067-040 São Paulo, SP, Brasil

e-mail: taecotoma@uol.com.br

\section{Sandra Luzia de Souza Alencar}

Mestre e doutoranda em Psicologia Social no Programa de Estudos Pós-Graduados em Psicologia Social da Pontifícia Universidade Católica de São Paulo - PUC-SP (São Paulo, SP, Brasil); vinculada ao Núcleo de Pesquisa Violência, Política e Sujeito da mesma Universidade; psicóloga da Secretaria Municipal de Saúde de São Paulo (São Paulo, SP, Brasil).

Rua Paracuê, 46/32 - Sumaré 01257-050 São Paulo, SP, Brasil

e-mail: sandra.Isalencar@gmail.com 